\title{
The ticking tail: daily oscillations in mRNA poly(A) tail length drive circadian cycles in protein synthesis
}

\author{
Ivana Gotic ${ }^{1}$ and Ueli Schibler ${ }^{1}$ \\ Department of Molecular Biology, National Centre of Competence in Research "Frontiers in Genetics," University of Geneva, \\ CH-1211 Geneva-4, Switzerland
}

In this issue of Genes \& Development, Kojima and colleagues (pp. 2724-2736) examined the impact of mRNA poly(A) tail length on circadian gene expression. Their study demonstrates how dynamic changes in transcript poly(A) tail length can lead to rhythmic protein expression, irrespective of whether mRNA accumulation is circadian or constitutive.

Circadian clocks are timing devices that enable organisms to adjust their physiology in a proactive manner to daily oscillations in environmental conditions caused by the rotation of the Earth around its own axis. In higher organisms, virtually every cell in the body possesses a self-sustained, cell-autonomous clockwork circuitry that is thought to be based on multiple interconnected gene expression loops (for review, see Dibner et al. 2010). Over the past decade, the transcriptional regulation underlying rhythmic mRNA and protein expression has been the main focus of circadian gene expression studies in various organisms (for review, see Lowrey and Takahashi 2004; Pegoraro and Tauber 2011). However, recent studies employing genome-wide analyses of transcription and mRNA accumulation could attribute only a minor fraction of daily mRNA expression cycles to rhythmic transcription (Koike et al. 2012; Menet et al. 2012). Moreover, only about half of the proteins with circadian accumulation cycles in mouse livers were found to be generated by cyclically expressed mRNAs (Reddy et al. 2006). Indeed, several groups have already initiated work on diurnal post-transcriptional mechanisms, and, based on their studies, it appears that many steps in the lifetime of an mRNA can be subject to circadian regulation. These steps, schematically illustrated in Figure 1, include regulation of pre-mRNA splicing efficiency (Low et al. 2008), alternative splicing (McGlincy et al. 2012; Wang et al.

[Keywords: circadian; polyadenylation; deadenylation; post-transcriptional mechanism]

${ }^{1}$ Corresonding authors

E-mail ueli.schibler@unige.ch

E-mail ivana.gotic@unige.ch

Article is online at http://www.genesdev.org/cgi/doi/10.1101/gad.210690.112.
2012), poly(A) site selection (Sumiyoshi et al. 2011), mRNA editing (Hughes et al. 2012), nuclear export (Morf et al. 2012), mRNA stability, and translation efficiency (Gatfield et al. 2009; Guo et al. 2009; Kojima et al. 2010; Woo et al. 2011; Mehta and Cheng 2012; Vodala et al. 2012; for review, see Kojima et al. 2011; Zhang et al. 2011).

The study by Kojima et al. (2012) in this issue of Genes \& Development adds yet another important mRNA processing step-namely, poly(A) tail length regulation-to the growing list of circadian post-transcriptional mechanisms (Fig. 1). Polyadenylation is an important determinant of eukaryotic mRNA stability and translation efficiency (for review, see Zhang et al. 2010). In the nucleus, poly(A) tails of $\sim 250-300$ adenosine residues are added to the nascent transcripts by poly(A) polymerase after the endonucleolytic cleavage at polyadenylation sites. These poly(A) stretches are then bound by poly(A)binding proteins (PABPs), which supposedly protect the transcripts from precocious degradation by the exosome but also fulfill other functions associated with mRNA maturation (Lemay et al. 2010). In general, the length of the poly(A) tail is still large in freshly exported mature mRNA but gets subsequently shortened in most mRNAs in a transcript- and cell type-specific manner. According to current models, the PABP-decorated poly(A) tail not only protects transcripts from exonucleolytic degradation, but also facilitates translation initiation through the formation of a closed loop between PABPs and the 5' capbound translation initiation factor 4F complex (eIF4F) (for review, see Millevoi and Vagner 2010; Weill et al. 2012). Aging transcripts progressively lose their poly(A) tails through the action of poly(A) nucleases (PANs, PARN, and the CCR4-NOT complex). The consecutive loss of protective PABPs exposes their $5^{\prime}$ ends to the activity of decapping enzymes, such as the Dcp1p-Dcp2p complex and DcpS (for review, see Parker and Song 2004). Deadenylated and decapped mRNAs are then targeted for degradation via the exosome or Xrn pathways $\left(3^{\prime}-5^{\prime}\right.$ or 5'-3' nucleolytic activity, respectively) (for review, see Sloan et al. 2012). However, shortening of poly(A) tails does not inevitably lead to transcript degradation. Under 


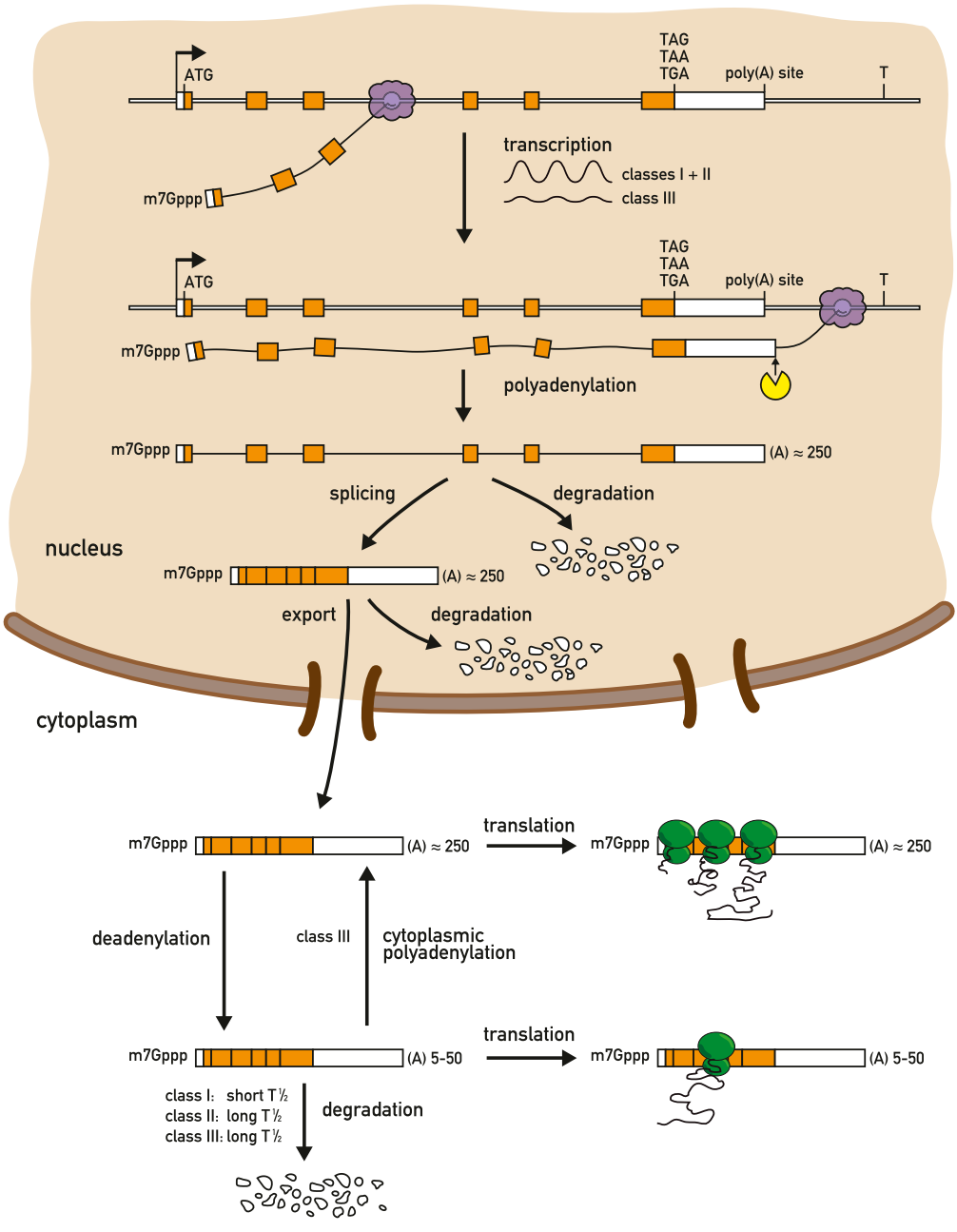

Figure 1. Mechanisms underlying the circadian activity of PAR transcripts. In mouse livers, PAR mRNAs are rhythmically (class I and class II) or constitutively (class III) transcribed by RNA polymerase II. The m7Gppp-capped nascent chains are released from the chromatin by endonucleolytic cleavage at the poly(A) site. Subsequently, the nuclear polyadenylation machinery adds $\sim 250$ A residues to the $3^{\prime}$ end of the transcripts. The polyadenylated precursors are then spliced into mature mRNAs, which are exported into the cytoplasm (note that some transcripts may undergo cotranscriptional splicing, not shown in the cartoon). As indicated in the scheme, some transcripts are degraded before being spliced or exported into the cytoplasm. In the cytoplasm, the long-tailed transcripts are translated more efficiently than the short-tailed transcripts. The latter are either degraded (class I and class II) or readenylated in a circadian fashion (class III). some circumstances (for example, in oocytes, neurons, and lymphocytes), mRNAs can be deadenylated and stored for extended time periods before they are readenylated and actively translated. This process is mediated through the interaction of transcript-specific cytoplasmic polyadenylation elements (CPEs), mainly present in the $3^{\prime}$ untranslated regions of mRNAs and their cognate binding proteins (CPEBs). Reactivation of stored silent transcripts includes the readenylation, initiated through the interaction of CEPBs with cytoplasmic polyadenylation complexes, as well as adenylation-independent mechanisms (e.g., DAZL-PABP and SLBP-eIF4G-mediated transcript stabilization) (for review, see Weill et al. 2012). In addition to the above-mentioned scenarios of cytoplasmic polyadenylation, the circadian expression pattern of a deadenylase named Nocturnin (Wang et al. 2001; Kojima et al. 2010) and daily poly(A) tail length variations in two mRNAs observed in previous studies (Robinson et al. 1988; Gerstner et al. 2012) suggested an implication of cytoplasmic poly(A) length regulation in circadian gene expression. In this study, Kojima et al. (2012) examined the connection between circadian transcript oscillations and poly(A) tail length dynamics in a genome-wide manner. Most interestingly, their work shows that rhythmic changes in poly(A) tail length of mRNAs accumulating at nearly constant levels throughout the day can drive circadian protein translation cycles.

To examine whether the length of poly(A) tails oscillates in a circadian fashion in mouse liver transcripts, Kojima et al. (2012) fractionated mRNAs harvested at 4-h intervals around the clock according to their elution properties on oligo(dT) columns. mRNAs harboring short (<60-nt) and long (60- to 250-nt) poly(A) tails can be eluted from such columns with moderate and low-salt concentrations, respectively. The fractionated mRNAs were then subjected to an oligonucleotide microarray hybridization analysis in order to estimate the prevalence of long-tailed or short-tailed transcripts in a daytimedependent manner. Their analysis identified 237 transcripts $(2.3 \%$ of expressed mRNAs) with rhythmic L/S (long/short) poly(A) tail length ratios, which were termed "poly(A) rhythmic" (PAR) mRNAs. The PAR transcripts were divided into three classes based on the temporal accumulation patterns of the corresponding pre-mRNAs (reflecting transcription) and mature mRNAs.

As anticipated, the most abundant PAR mRNAs /class I) showed circadian rhythmicity at all levels. High L/S poly(A) tail ratios of these transcripts at specific time 
points likely reflect circadian synthesis, as pre-mRNAs and newly synthesized mRNAs carry longer poly(A) tails than aged ones. An intriguing observation in this group of PAR transcripts is the $\sim 5$-h delay between maximal premRNA and mRNA accumulation. Since this delay appears to be much shorter for the majority of rhythmic transcripts, additional experiments will be required to examine the mechanisms specifically retarding the accumulation of PAR mRNAs after their synthesis.

Class II PAR transcripts exhibited circadian rhythmicity at the pre-mRNA and poly(A) tail length levels but, supposedly owing to their long half-lives, accumulated at virtually constant amounts throughout the day. The daily rise and fall in the $\mathrm{L} / \mathrm{S}$ tail ratio of class II transcripts most probably reflect their circadian transcription, as has been argued for class I transcripts. Since long poly(A) tails may be beneficial for translation, the oscillations in poly(A) tail length could manifest themselves in protein synthesis rhythms and hence in circadian protein accumulation. Immunoblot experiments for MIF and GSTT2, two polypeptides encoded by class II PAR mRNA, are consistent with this scenario. Interestingly, some class II PAR mRNAs display maximum poly(A) tail lengths at the opposite time of the day, probably reflecting a regulation of their transcription by anti-phasic circadian feedback loops.

Clearly, class III PAR mRNAs are the least expected and thus the most interesting PAR transcripts. These mRNAs are characterized by daily oscillations in their poly(A) tail length in the absence of significant temporal changes in pre-mRNA and mRNA levels. Hence, for these transcripts, cytoplasmic polyadenylation must participate in the generation of circadian poly(A) tail length fluctuations and, as a consequence, protein synthesis rhythms. As shown by this study, circadian cytoplasmic polyadenylation of a subset of class III transcripts is mediated by the known CPEB factors (CPEB1 and CPEB2). Interestingly, CPEB2 as well as other factors of the polyadenylation machinery (e.g., CPEB4, PARN, and GLD2) exhibit rhythmic changes in their mRNA expression. However, the investigators' data also suggest the existence of additional, yet-unknown mechanisms of cytoplasmic polyadenylation that do not exclusively rely on CPEB-mediated activity. The notion that class III PAR transcripts comprise a special group of mRNAs is further emphasized by their relatively long half-lives and the phase of their poly(A) length oscillation. While most class I and class II PAR transcripts exhibit maximal poly(A) tail lengths during the night, class III PAR mRNAs reach longest poly(A) tails during the day. In future studies, it will be exciting to identify all of the cisacting RNA sequences and their cognate trans-acting factors and dissect the mechanisms by which they control the cytoplasmic oscillations in poly(A) length of class III PAR transcripts.

In conclusion, the study by Kojima et al. (2012) opens new avenues in studying circadian gene expression by demonstrating that cyclic protein expression can be generated by rhythmic changes in poly(A) tail length of both rhythmically and constitutively expressed mRNAs (see Fig. 1). Probably due to the limitations of the microarray technology used (for review, see Sun et al. 2012), no PAR transcript-specific sequence motifs could yet be identified. However, the use of ultradeep RNA sequencing procedures might help address these issues in the near future.

\section{Acknowledgments}

We thank Nicolas Roggli for the artwork.

\section{References}

Dibner C, Schibler U, Albrecht U. 2010. The mammalian circadian timing system: Organization and coordination of central and peripheral clocks. Annu Rev Physiol 72: 517-549.

Gatfield D, Le Martelot G, Vejnar CE, Gerlach D, Schaad O, Fleury-Olela F, Ruskeepaa AL, Oresic M, Esau CC, Zdobnov EM, et al. 2009. Integration of microRNA miR-122 in hepatic circadian gene expression. Genes Dev 23: 1313-1326.

Gerstner JR, Vanderheyden WM, LaVaute T, Westmark CJ, Rouhana L, Pack AI, Wickens M, Landry CF. 2012. Time of day regulates subcellular trafficking, tripartite synaptic localization, and polyadenylation of the astrocytic Fabp7 mRNA. I Neurosci 32: 1383-1394.

Guo J, Cheng P, Yuan H, Liu Y. 2009. The exosome regulates circadian gene expression in a posttranscriptional negative feedback loop. Cell 138: 1236-1246.

Hughes ME, Grant GR, Paquin C, Qian J, Nitabach MN. 2012. Deep sequencing the circadian and diurnal transcriptome of Drosophila brain. Genome Res 22: 1266-1281.

Koike N, Yoo SH, Huang HC, Kumar V, Lee C, Kim TK, Takahashi JS. 2012. Transcriptional architecture and chromatin landscape of the core circadian clock in mammals. Science 338: 349-354.

Kojima S, Gatfield D, Esau CC, Green CB. 2010. MicroRNA-122 modulates the rhythmic expression profile of the circadian deadenylase Nocturnin in mouse liver. PLOS ONE 5: e11264.

Kojima S, Shingle DL, Green CB. 2011. Post-transcriptional control of circadian rhythms. J Cell Sci 124: 311-320.

Kojima S, Sher-Chen EL, Green CB. 2012. Circadian control of mRNA polyadenylation dynamics regulates rhythmic protein expression. Genes Dev (this issue). doi: 10.1101/gad. 208306.112.

Lemay JF, Lemieux C, St-Andre O, Bachand F. 2010. Crossing the borders: Poly(A)-binding proteins working on both sides of the fence. RNA Biol 7: 291-295.

Low KH, Lim C, Ko HW, Edery I. 2008. Natural variation in the splice site strength of a clock gene and species-specific thermal adaptation. Neuron 60: 1054-1067.

Lowrey PL, Takahashi JS. 2004. Mammalian circadian biology: Elucidating genome-wide levels of temporal organization. Annu Rev Genomics Hum Genet 5: 407-441.

McGlincy NJ, Valomon A, Chesham JE, Maywood ES, Hastings MH, Ule J. 2012. Regulation of alternative splicing by the circadian clock and food related cues. Genome Biol 13: R54.

Mehta N, Cheng HY. 2012. Micro-managing the circadian clock: The role of microRNAs in biological timekeeping. J Mol Biol doi: $10.1016 /$ j.jmb.2012.10.022.

Menet JS, Rodriguez J, Abruzzi KC, Rosbash M. 2012. NascentSeq reveals novel features of mouse circadian transcriptional regulation. eLife 1: e00011.

Millevoi S, Vagner S. 2010. Molecular mechanisms of eukaryotic pre-mRNA 3' end processing regulation. Nucleic Acids Res 38: 2757-2774. 
Morf J, Rey G, Schneider K, Stratmann M, Fujita J, Naef F, Schibler U. 2012. Cold-inducible RNA-binding protein modulates circadian gene expression posttranscriptionally. Science 338: 379-383.

Parker R, Song H. 2004. The enzymes and control of eukaryotic mRNA turnover. Nat Struct Mol Biol 11: 121-127.

Pegoraro M, Tauber E. 2011. Animal clocks: A multitude of molecular mechanisms for circadian timekeeping. Wiley Interdiscip Rev RNA 2: 312-320.

Reddy AB, Karp NA, Maywood ES, Sage EA, Deery M, O'Neill JS, Wong GK, Chesham J, Odell M, Lilley KS, et al. 2006. Circadian orchestration of the hepatic proteome. Curr Biol 16: $1107-1115$.

Robinson BG, Frim DM, Schwartz WJ, Majzoub JA. 1988. Vasopressin mRNA in the suprachiasmatic nuclei: Daily regulation of polyadenylate tail length. Science 241: 342344.

Sloan KE, Schneider C, Watkins NJ. 2012. Comparison of the yeast and human nuclear exosome complexes. Biochem Soc Trans 40: 850-855.

Sumiyoshi M, Sato S, Takeda Y, Sumida K, Koga K, Itoh T, Nakagawa H, Shimohigashi Y, Shimohigashi M. 2011. A circadian neuropeptide PDF in the honeybee, Apis mellifera: cDNA cloning and expression of mRNA. Zoolog Sci 28: 897909.

Sun Y, Fu Y, Li Y, Xu A. 2012. Genome-wide alternative polyadenylation in animals: Insights from high-throughput technologies. J Mol Cell Biol doi: 10.1093/jmcb/mjs041.

Vodala S, Pescatore S, Rodriguez J, Buescher M, Chen YW, Weng R, Cohen SM, Rosbash M. 2012. The oscillating miRNA 959964 cluster Iimpacts Drosophila feeding time and other circadian outputs. Cell Metab 16: 601-612.

Wang Y, Osterbur DL, Megaw PL, Tosini G, Fukuhara C, Green CB, Besharse JC. 2001. Rhythmic expression of Nocturnin mRNA in multiple tissues of the mouse. BMC Dev Biol 1:9.

Wang X, Wu F, Xie Q, Wang H, Wang Y, Yue Y, Gahura O, Ma S, Liu L, Cao Y, et al. 2012. SKIP is a component of the spliceosome linking alternative splicing and the circadian clock in Arabidopsis. Plant Cell 24: 3278-3295.

Weill L, Belloc E, Bava FA, Mendez R. 2012. Translational control by changes in poly(A) tail length: Recycling mRNAs. Nat Struct Mol Biol 19: 577-585.

Woo KC, Kim TD, Lee KH, Kim DY, Kim S, Lee HR, Kang HJ, Chung SJ, Senju S, Nishimura Y, et al. 2011. Modulation of exosome-mediated mRNA turnover by interaction of GTPbinding protein 1 (GTPBP1) with its target mRNAs. FASEB $J$ 25: 2757-2769.

Zhang X, Virtanen A, Kleiman FE. 2010. To polyadenylate or to deadenylate: That is the question. Cell Cycle 9: 4437-4449.

Zhang L, Weng W, Guo J. 2011. Posttranscriptional mechanisms in controlling eukaryotic circadian rhythms. FEBS Lett 585: 1400-1405. 


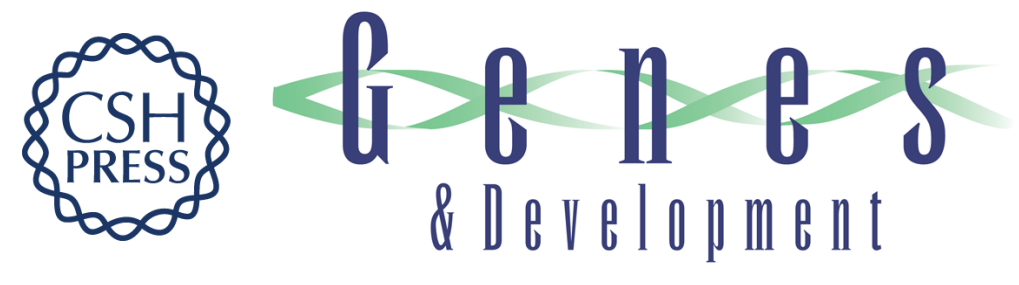

\section{The ticking tail: daily oscillations in mRNA poly(A) tail length drive circadian cycles in protein synthesis}

Ivana Gotic and Ueli Schibler

Genes Dev. 2012, 26:

Access the most recent version at doi:10.1101/gad.210690.112

\section{Related Content Circadian control of mRNA polyadenylation dynamics regulates rhythmic protein expression \\ Shihoko Kojima, Elaine L. Sher-Chen and Carla B. Green \\ Genes Dev. December , 2012 26: 2724-2736 \\ References This article cites 28 articles, 9 of which can be accessed free at: \\ http://genesdev.cshlp.org/content/26/24/2669.full.html\#ref-list-1 \\ Articles cited in: \\ http://genesdev.cshlp.org/content/26/24/2669.full.html\#related-urls \\ License \\ Email Alerting \\ Receive free email alerts when new articles cite this article - sign up in the box at the top Service

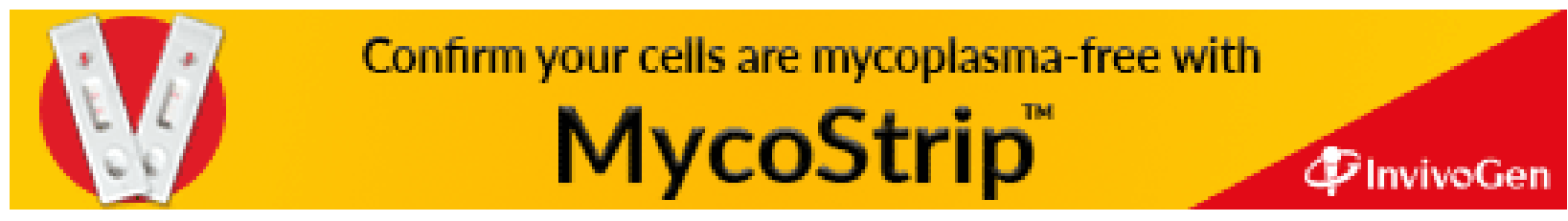

